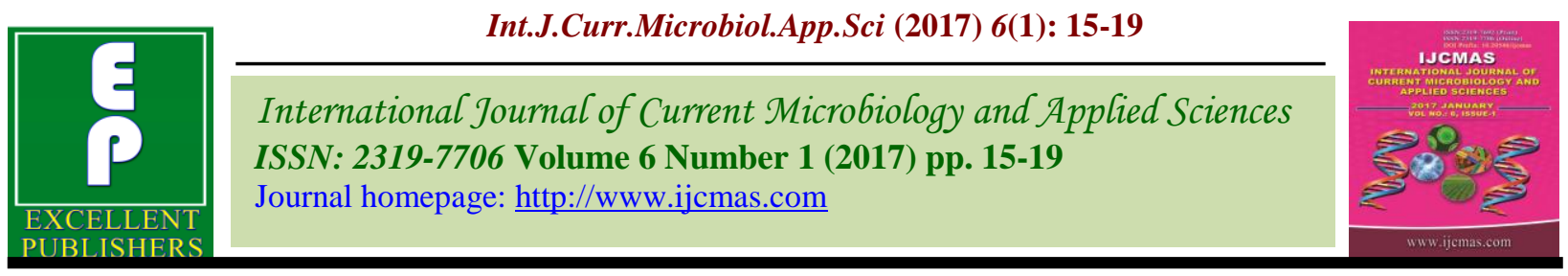

Original Research Article

http://dx.doi.org/10.20546/ijcmas.2017.601.002

\title{
Age Related Changes in T Cell Subsets in Thymus and Spleen of Layer Chicken (Gallus domesticus)
}

\author{
T.A. Kannan ${ }^{1}$, Geetha Ramesh ${ }^{2}$, S. Ushakumari ${ }^{2}$, G. Dhinakarraj ${ }^{3}$ and S. Vairamuthu ${ }^{4}$ \\ ${ }^{1}$ Centre for Stem Cell Research and Regenerative Medicine Tamil Nadu Veterinary and Animal \\ Sciences University, Madras Veterinary College, Chennai- 600 007, India \\ ${ }^{2}$ Department of Veterinary Anatomy, Tamil Nadu Veterinary and Animal Sciences University, \\ Madras Veterinary College, Chennai- 600 007, India \\ ${ }^{3}$ Translational Research Platform - Veterinary Biologicals, Tamil Nadu Veterinary and Animal \\ Sciences University, Chennai- 600 051, India \\ ${ }^{4}$ Centralised Instrumentation laboratory, Tamil Nadu Veterinary and Animal Sciences \\ University, Madras Veterinary College, Chennai- 600 007, India \\ *Corresponding author
}

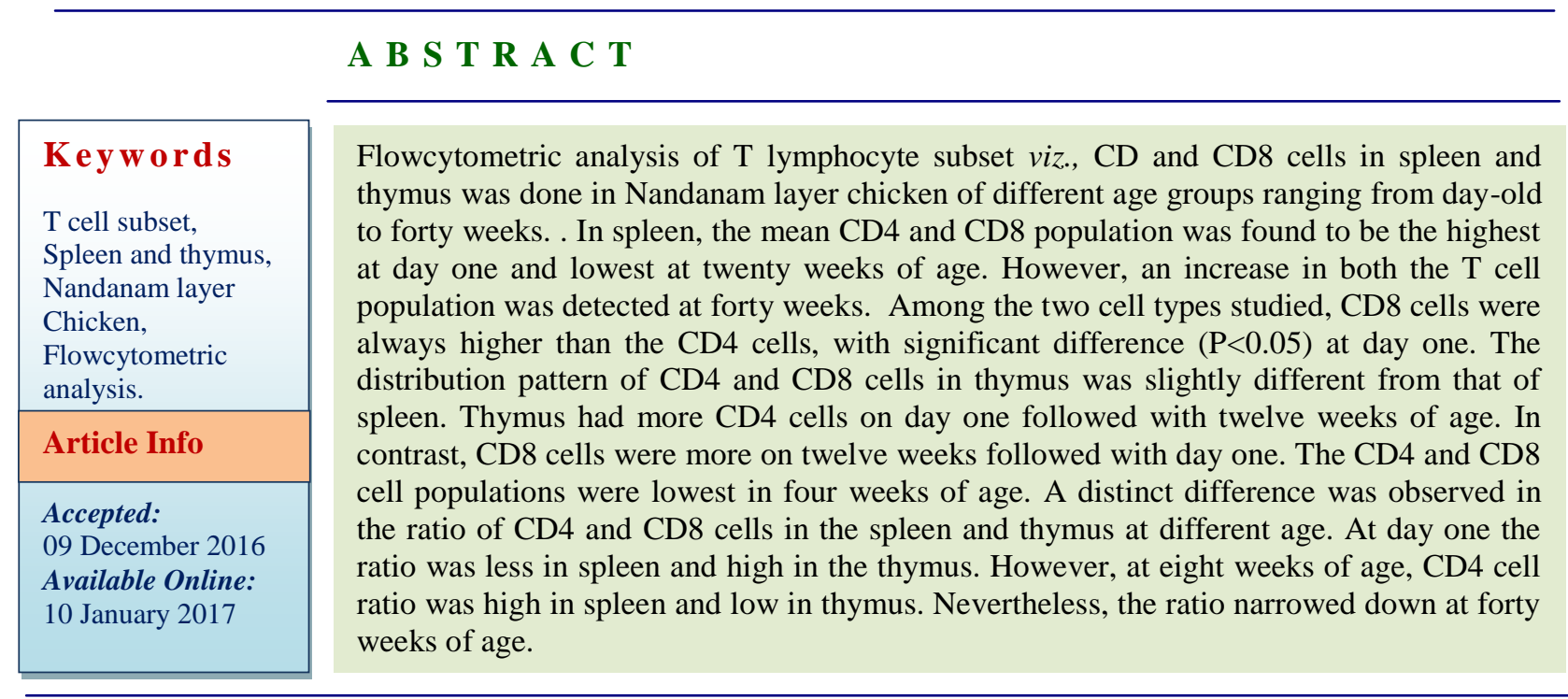

\section{Introduction}

Similar to mammalian species, chicken T-cell populations can be delineated into subsets based on their expression of cell surface proteins. T-cell subsets are broadly defined by the expression of molecules such as CD4, CD8 and T-cell receptor (Erf et al., 1998). Major differentiation events regarding T-cell development in the thymus appear to be conserved between chickens and mammalian species. Mature CD4 or CD8 single-positive T-cells leave the thymus, populate secondary immune organs, and travel in the circulatory and lymphatic systems. Most CD4+ cells are helper T-cells responding to exogenous antigen in association with major histo compatibility complex (MHC) class II molecules; whereas, CD8+ cells respond to endogenous antigen in association with MHC 
class I molecules and generally function as cytotoxic T-cells (Gobel, 1996).

Thymus is the central lymphoid organ occurs in all vertebrate species, situated on either side of the neck, close to the jugular vein (King, 1983). Bone marrow-derived T-cell precursors undergo differentiation, maturation eventually leading to migration of positively selected thymocytes to the peripheral lymphoid organs such as the spleen (Savino and Dardenne, 2000 and Varga et al., 2009) and GALT including the caecal tonsil and the lymph nodes (Ciriaco et al., 2003; Gail Pearse, 2006 and Karen Staines et al., 2013).

Spleen is the principal organ of systemic immunity and its importance in disease resistance is accentuated by the scarcity of avian lymph nodes. The avian spleen functions as a major blood filtering organ and is the major source of antibody production. It does not function as a reservoir of blood as in mammals and its function is not oriented towards supply of oxygen (Jeurissen, 1991). The spleen also plays an important role in erythrocyte destruction, phagocytosis and antigen-antibody interactions (Burke and Simon, 1970).

Due to genetic and environmental differences, avian immune developmental and functional aspects established for layers may differ from broilers. Considering their economic importance, a better understanding of the immune system in broiler chickens is essential.

Nandanam chicken is a dual purpose, colored variety with good disease resistance and most popular among poultry farmers due to its adaptability to backyard farming. Nandanam strain was developed in Poultry Research Station, Tamil Nadu Veterinary and Animal Sciences University, Chennai. Hence, the present study was to find out the relative proportions of CD4 and CD8 cell populations present in the thymus and spleen of different age groups of Nandanam chicken by using flow cytometry.

\section{Materials and Methods}

Materials for this study were collected from six different age groups of Nandanam layer chickens such as day-old, four, eight, twelve, twenty and forty weeks ( $n=6$; each group). All birds were maintained in a healthy environment at Institute of Poultry Production management, TANUVAS, Chennai. The birds appeared healthy and did not show any clinical signs of disease. The birds were euthanized by high cervical dislocation and thymic lobes and spleen were removed for phenotypic analysis of lymphocytes.

To evaluate the lymphocyte populations, single cell suspensions were prepared by finely mincing the thymic and spleenic tissue and filter it through 60 micron filters $(\mathrm{Wu}$ et al., 2000) and the cell concentration was adjusted to $1.5 \times 10^{6}$ cells/ml in RPMI-1640 medium. Then the cells were stained by a single colour immunostining procedure using a panel of monoclonal antibodies $(\mathrm{mAb})$ as per Chan et al. (1988). The mAb panel included mouse anti-chicken CD4: FITC (Cat. No. Serotec MICA 2164F) and mouse antichicken CD8a: FITC (Cat. No. Serotec MCA-2166F) that recognize the avian CD4 and CD8, respectively.

The stained cells were then read in the FACS caliber Flow cytometer (Becton and Dickinson, USA). The lymphocytes were gated based on the FSC and SSC characteristics and using the PBS control cells. The background florescence was set as M1 and the fluorescence was set as M2. Percentage of M2 values for different monoclonal antibodies was recorded from the single parameter histogram. The ratio of CD4 
and CD8 was calculated by dividing percentage of CD4 cells by percentage of CD8 cells.

Statistical analysis was carried out using statistical analysis software (Systat Inc., Evanston, IL). Test results were considered significant of $\mathrm{P}<0.01$. All data were expressed as the mean \pm S.E.

\section{Results and Discussion}

In the present study by flow cytometric analysis, the CD4 and CD8 count was recorded in the normal spleen and thymus of different age groups of layer chicken (Figure1 and 2). In spleen, the mean CD4 and CD8 population was found to be the highest at day one and lowest at twenty weeks of age.

Fig.1 Mean CD4 and CD8 T cells in Spleen of different age groups

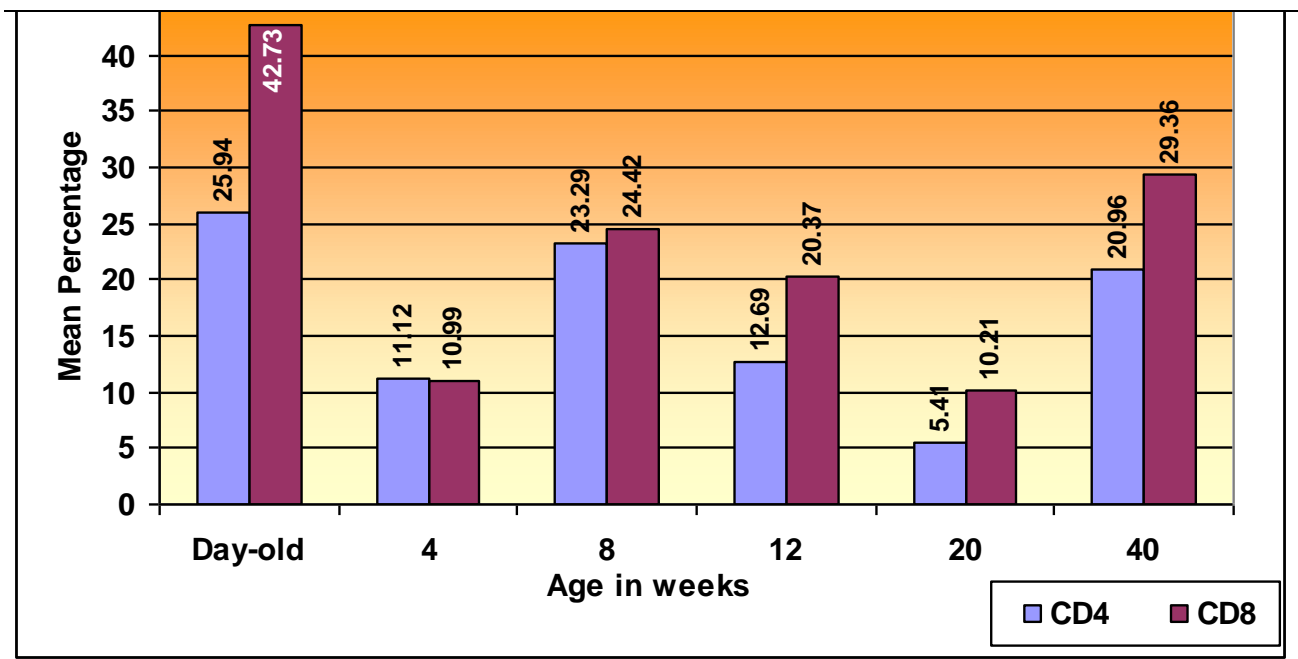

Fig.2 Mean CD4 and CD8 T cells in Thymus of different age groups

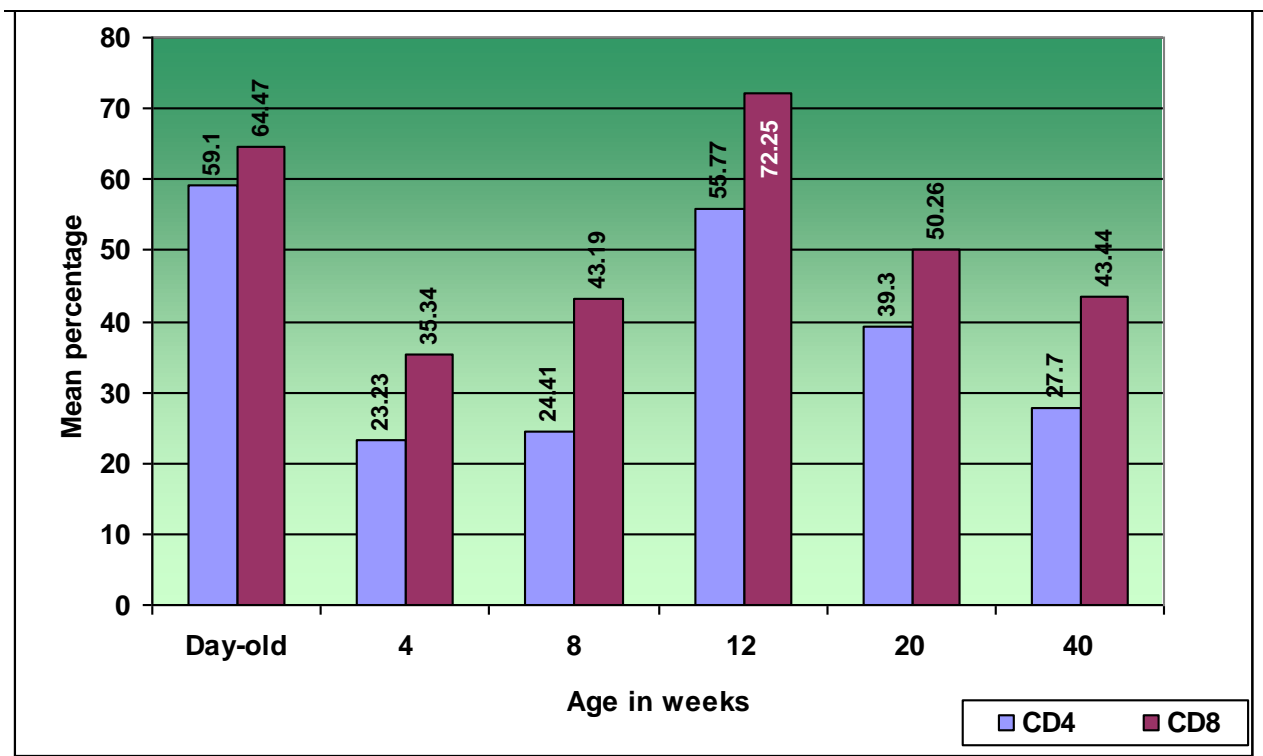


Fig.3 CD4 and CD8 T cell ratios in Spleen and Thymus of different age groups

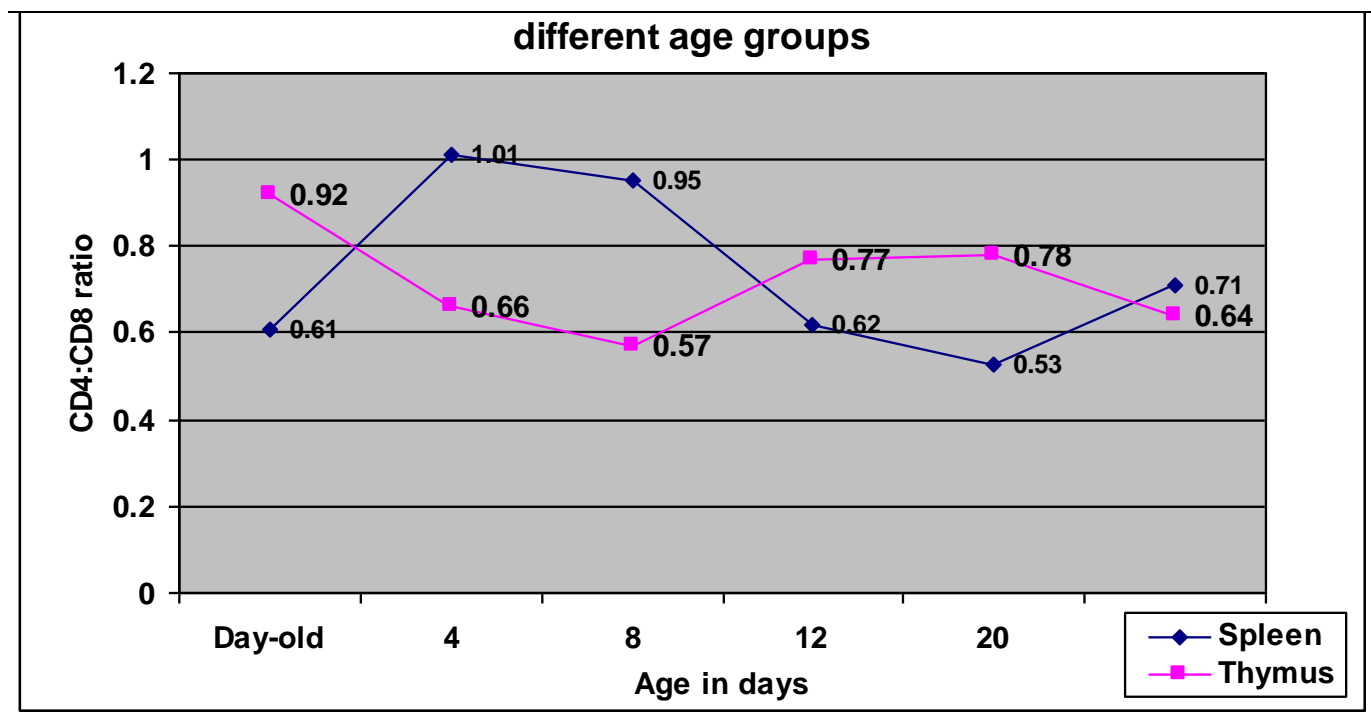

Nevertheless, an increase in both the $\mathrm{T}$ cell population was detected at forty weeks of age. Bridle et al., (2006) have detected an increase in the circulating CD4 and CD8 T cell populations by eighty weeks. Although we have not assessed the circulating $\mathrm{T}$ cell populations in our study, the increase in the population of these cells in spleen at two hundred days concurs with the findings of Bridle et al., (2006). Among the two cell types studied, CD8 cells were always higher than the CD4 cells, with significant difference $(\mathrm{P}<0.05)$ at day one.

The distribution pattern of CD4 and CD8 cells in thymus was slightly different from that of spleen. Thymus had more CD4 cells on day one followed with twelve weeks of age. In contrast, CD8 cells were more on twelve weeks followed with day one. CD4 and CD8 cell populations were lowest on four weeks. Although we did not observe any set pattern of distribution of these cell types in the spleen and thymus of normal chicken, the results we have recorded concurs with some of the earlier reports (Davidson and Boyd, 1992) in that substantial populations of these cells could be detected at two and seven weeks of age.
In the present study the CD4 and CD8 ratio at four weeks of age was 1.01 in spleen and 0.67 in thymus whereas the reverse condition was recorded by Erf (1997) in spleen and thymus of commercial broilers and specific pathogen single comb white leghorn birds.

Similarly, CD4 and CD8 ratio in spleen was decreased from four weeks of age (1.01) to eight weeks of age (0.95). Erf et al., (1998) recorded decreased in CD4 and CD8 ratio between two and seven weeks of age in commercial broiler chicken. Further Erf et al. (1998) also found that there was an increase CD4 and CD8 ration in thymus between two weeks (1.20) and seven weeks (2.30). A similar increase CD4 and CD8 ratio in thymus was observed in the present study between four weeks (0.67) and eight weeks (0.72).

A distinct difference was observed in the ratios of CD4 and CD8 cells in the spleen and thymus at different age. At day one the ratio was less in spleen and high in the thymus. However, at eight weeks, the CD4 and CD8 cell ratio was high in spleen and low in thymus. Nevertheless, the ratios narrowed down at forty weeks of age. The relationship between the mean CD4 and CD8 values in 
spleen and thymus of different age groups were shown (Figure- 3).

\section{Acknowledgements}

The authors are thankful to the Professor and Head, Dept. of Animal Biotechnology and Dean, Madras Veterinary College for providing facilities to carry out this work.

\section{References}

Bridle, B.W., R. Julian, P.E. Shewen, J.P. Vaillancourt and A.K. Kaushik. 2006. $\mathrm{T}$ lymphocyte subpopulations diverge in commercially raised chickens. Can. J. Vet. Res., 70: 183-90.

Burke, J.S. and Simon, G.T. 1970. Electron Microscopy of the Spleen. I. Anatomy and Microcirculation. Am. J. Pathol., 58: 127-55.

Chan, M.M., Chen, C.H. Ager L.L. and Cooper, M.D. 1988. Avian homologues of mammalian CD4 and CD8 antigens. $J$. Immunol., 148: 2135-2140.

Ciriaco, E., Pinera, P.P. Diaz-Esnal, B and Laura, R. 2003.Age related changes in the avian primary lymphoid organs (Thymus and Bursa of fabricius). Microscopic Res. Techniques, 62: 482-487.

Davidson, N.J. and R.L. Boyd, 1992. Delineation of chicken thymocytes by CD3-TCR complex, CD4 and CD8 antigen expression reveals phylogenically conserved and novel thymocyte subsets. Int. Immunol., 4: 1175 - 82.

Erf, G.F., 1997. Immune system function and development in broilers. Poultry Science, $109-123$.
Erf, G.F., Botje, W.G. and Bersi, T.K. 1998. CD4, CD8 and TCR defined $\mathrm{T}$ cell subsets in thymus and spleen of 2 and 7 week-old commercial broiler chickens. Vet. Immunol. Immunopathol., 61: 320332.

Gail Pearse, 2006. Normal structure, function and histology of the thymus. Toxicol. Pathol., 34: 504-514.

Gobel, T.W.F. 1996. The T dependent immune system In: Poultry Immunology, Poultry science symposium series, (Eds.) Davison, T.F., T.R. Moris and L.N. Payne. 24: 31-45.

Jeurissen, S.H.M. 1991. Structure and Function of the Chicken Spleen. Res. Immunol., $142 ; 352-55$.

Karen Staines, J.R. Young and Colin Butler. 2013. Expression of Chicken DEC205 Reflects the Unique Structure and Function of the Avian Immune System. PLOS ONE, Vol. 8: (1).

Savino, W. and M. Dardenne. 2000. Neuroendocrine control of thymus physiology. Endocrine Reviews, 21: 41243.

Varga, I., Mikusova, R., Pospisilova, V., Galfiova, P., Adamkov, M., Polak, S. and Galbavy, S. 2009. Morphologic heterogeneity of human thymic nonlymphocytic cells. Neuro Endocrinol. Lett., 30(3): 275-83.

Wu, C.C., Dorairajan, T. and Linn, T.L. 2000. Effect of ascorbic acid supplementation on the immune response of chickens vaccinated and challanged with IBD virus. Vet. Immunol. Immunopathol., 74: 145-152.

\section{How to cite this article:}

Kannan, T.A., Geetha Ramesh, S. Ushakumari, G. Dhinakarraj and Vairamuthu, S. 2017. Age Related Changes in T Cell Subsets in Thymus and Spleen of Layer Chicken (Gallus domesticus). Int.J.Curr.Microbiol.App.Sci. 6(1): 15-19. doi: http://dx.doi.org/10.20546/ijcmas.2017.601.002 